\title{
AS REDES DE CONVERSAÇÕES ENTRE LICENCIANDOS COMO AGÊNCIA PARA PENSAR OS ENCONTROSFORMAÇÃO COM PROFESSORES: UMA EXPERIÊNCIA NO IFES
}

\author{
Priscila dos Santos Moreira \\ Doutoranda em Educação pelo Programa de Pós-Graduação em Educação da Universidade Federal \\ do Espírito Santo (PPGE/UFES). Pedagoga do Instituto Federal de Educação, Ciência e Tecnologia \\ do Espírito Santo (IFES). Integrante do Grupo de Pesquisa Currículos, Culturas, Linguagens e \\ Formação de Professores. \\ https://orcid.org/0000-0002-9685-1517 \\ Janete Magalhães Carvalho \\ Doutora em Educação pela Universidade Federal do Rio de Janeiro (UFRJ). Pós-doutorado em \\ Currículo pela Universidade do Estado do Rio de Janeiro (UERJ) e em Sociologia da Vida \\ Cotidiana pelo Instituto de Ciências Sociais da Universidade de Lisboa (ICS/UL). Professora do \\ PPGE/UFES. Pesquisadora 1D-CNPq. Coordenadora do Grupo de Pesquisa Currículos, Culturas, \\ Linguagens e Formação de Professores. \\ https://orcid.org/0000-0001-9906-2911
}

\section{RESUMO}

Este artigo objetiva acompanhar as redes de conversações em um curso de licenciatura do Instituto Federal do Espírito Santo (Ifes), tecendo relações entre os campos do currículo e da formação com licenciandos, questionando nos encontrosformação a ênfase na solução ou na invenção de problemas. A partir da filosofia da diferença de Gilles Deleuze e Félix Guattari, a cartografia foi produzida entrelinhas do desejo e processos (des)(re)territorializantes, com vistas à propagação do que pode um corpo em encontrosformação na educação básica por meio do Estágio Supervisionado. A pesquisa evidenciou que as avaliações externas Paebes e Enem influenciam os processos formativos pela predominância de uma lógica neotecnicista, atrelada à recognição, ao par perguntas-respostas prontas e aosafetos tristes que enrijecem esse desenho curricular. O estudo enfatiza, entretanto, a emergência da singularidade e da diferença produzindo invenção de outros possíveis que rompem essa racionalidade. Entreformas, fluxos e forças, defende politicaspráticas e teoriaspráticas como indissociáveis, fazendo ressoar, para além dos processos recognitivos, a inventividade presente no Estágio Supervisionado e vibrar bons encontrosformação por meio de processos inventivos.

Palavras-chave: Currículo. Formação. Licenciaturas. Institutos Federais.

\section{THE NETWORKS OF CONVERSATIONS BETWEEN LICENSES AS AN AGENCY TO THINK THE MEETINGS WITH TEACHERS: AN EXPERIENCE AT IFES}

\begin{abstract}
The article aims at monitoring the conversation networks within a degree course at the Federal Institute in the State of Espírito Santo (Ifes), establishing relations between the curriculum fields and the graduates formation, questioning, during the training (formation)meetings the emphasis given to the troubleshooting or the invention of problems. From Gilles Deleuze and Félix Guattari philosophy of difference, mapping was produced between the lines of desire and (de)(re)territorializing processes, in order to the propagation of what a body is able to do when training(formation)meetings in elementary education through Supervised Practice. The research highlighted that outside assessments, such as, Paebes and Enem have some influence in the formative processes by the predominance of a neotechnicist logic, linked to the recognition, at par ready questions-answers and sad affections that stiffen this curricular design. However, the study stands out the emergence for singularity and difference producing the invention of other possibilities that break such rationality. Among shapes, flows and forces, it defends practicalpolicies and practicaltheories as inseparable, causing it to resound beyond the recognitive
\end{abstract}


processes, the present inventiveness regarding the Supervised Practice and the vibration of good trainingmeetings through inventive processes.

Keywords: Curriculum. Training. Degree Courses. Federal Institutes.

\title{
LAS REDES DE CONVERSACIONES ENTRE LICENCIANDOS COMO AGENCIA PARA PENSAR LOS ENCUENTROSFORMACIÓN CON PROFESORES: UMA EXPERIENCIA EN EL IFES
}

\begin{abstract}
RESUMEN
Este artículo objetiva acompañar las redes de conversación en un curso de licenciatura del Instituto Federal del Espíritu Santo (Ifes), con el propósito de tejer relaciones entre los campos del currículo y formación con los licenciandos, y, además, cuestionar en los encuentrosformación el énfasis en la solución o en la invención de problemas. A partir de la filosofía de la diferencia de Gilles Deleuze y Félix Guattari, la cartografía fue producida entre líneas del deseo y procesos (des) territorializantes, con vistas a la propagación de posibilidades de un cuerpo en encuentrosformación, en la educación básica, en las Prácticas Supervisadas. La investigación evidenció que las evaluaciones externas Paebes e Enem influencian los procesos formativos por la predominancia de una lógica neotecnicista, vinculada a la recognición, al par de preguntasrespuestas hechas y a los afectos tristes que tensiona ese diseño curricular. El estudio enfatiza, no obstante, la emergencia de la singularidad y de la diferencia, produciendo invención de otras posibilidades que rompen con esa racionalidad. Entre formas, flujos y fuerzas, defiende políticasprácticas y teoríasprácticas como indisociables, haciendo resonar, para más allá de los procesos recognitivos, la inventiva presente en las Prácticas Supervisadas y vibrar buenos encuentrosformación mediante procesos inventivos.
\end{abstract}

Palabras clave: Currículo. Formación. Licenciaturas. Institutos Federales.

\section{Introdução}

Este artigo é decorrente de pesquisa cujo objetivo foi acompanhar os tracejados cartográficos em um curso de licenciatura do Instituto Federal de Educação, Ciência e Tecnologia do Espírito Santo (Ifes), entre linhas do desejo (DELEUZE; PARNET, 1998) e processos (des)(re)territorializantes (GUATTARI; ROLNIK, 2011), visando à propagação do que pode um corpo em encontrosformação com (futuros) professores para a educação básica no Estágio Supervisionado.

Inicialmente, problematizamos: é possível compor uma escrita-imanência, uma pesquisa no campo educacional que coloque os conceitos identitários sob suspeita e busque escapar da criação de novas identidades e representações totalizantes sobre "o que é ser professor", "como fazer formação de/com professores", "o que é currículo" e outras rostificações?" (DELEUZE, 1992). É possível rasurar as linearidades que perpassam as

\footnotetext{
${ }^{1} \mathrm{O}$ rosto (a rostidade) são as funções sociais. De modo constante, somos capturados em processos de rostificações; um ser/estar categorizado em imagens congeladas, em representações estigmatizadas e fixadas em determinado rosto/modelo com dicotomias sucessivas (DELEUZE; PARNET, 1998).
} 
noções de "formação inicial e continuada" (GARCIA; SUSSEKIND, 2011) e contribuir para fazer vibrar múltiplos modos de pensarfazer, ${ }^{2}$ currículo(s)diferença e encontrosformação com (futuros) professores?

Entendemos que a implicação é um conceito dinâmico que remete aos modos de existência engendrados à experimentaçãoanálise das paisagens, produzidos no afetar dos corpos. Dessa forma, não é possível representar quais delas nos movem na constituição de um campo problemático e de contextualização de uma pesquisa que não almeja se fixar como uma resposta única, diante dos questionamentos que transpassam o campo educacional. Nesse sentido, múltiplas e complexas realidades foram produzidas nesses territórios-licenciaturas que se (re)(des)fazem, de modos singulares e em processos de diferenciação, nas danças de fixação e de escapes nas tessituras das praticasteorias de aprendizagemensinoformação.

O número de unidades dos IFs foi triplicado nas duas últimas décadas e a oferta das licenciaturas também foi consideravelmente ampliada em consonância com os dados do Inep (2016) que informam que, em 2015, havia 430 cursos totalizando 45.140 matrículas em cursos presenciais e a distância: 19.233 na Região Nordeste, 10.163 na Região Sudeste, 6.311 na Região Norte, 4.947 na Região Centro-Oeste e 4.486 na Região Sul.

Especificamente no Espírito Santo (ES), dialogamos com os dados apresentados pelo observatório do Plano Nacional de Educação, referentes à "formação" dos que ministram aulas nos anos finais do ensino fundamental e no ensino médio: em menos de dez anos, o índice de professores com licenciatura mudou de $72,1 \%$ para $87,8 \%$ e, no ensino médio, de 78,2\% para 85,5\%. Esse período abarca aquele em que o Ifes iniciou a oferta dos cursos de licenciatura neste estado: Química em 2006 e Matemática em $2008^{3}$ no campus localizado na capital (Vitória).

Na década seguinte, conforme documento do Ifes, fornecido pela Pró-Reitoria de Ensino do Ifes para esta pesquisa, em que constam as matrículas de todos os cursos regulares de graduação, percebemos que, durante o ano em que este estudo foi realizado (2017/2 e 2018/1), ocorreram 50 ofertas desses cursos. Dessas, três são na modalidade de

\footnotetext{
${ }^{2}$ Inspiradas em Nilda Alves (2010), por meio da escrita, reforçamos a ideia de que pensamentos e ações, teorias e práticas, práticas e políticas, ensino e aprendizagem - e outras palavras que apreendemos como dicotomias/polaridades - são conceitos híbridos, indissociáveis.

${ }^{3}$ As duas ofertas iniciaram no período em que Luiz Inácio Lula da Silva estava na presidência do país.
} 
educação a distância (todas essas em licenciatura ou "complementação pedagógica" com vistas a "formar professores"). Das 47 presenciais, apenas 12 são licenciaturas. Todas as demais agregaram bacharelados (incluindo as Engenharias) e tecnólogos distribuídos nos 21 campi do Espírito Santo.

Essas 12 ofertas de curso de licenciatura presencial são compostas de oito cursos diversos distribuídos em dez campi da seguinte maneira: Alegre (Ciências Biológicas), Aracruz (Química), Cachoeiro do Itapemirim (Matemática), Cariacica (Física), Itapina (Ciências Agrícolas e Pedagogia), Nova Venécia (Geografia), Santa Teresa (Ciências Biológicas), Venda Nova do Imigrante (Letras Português), Vila Velha (Química) e Vitória (Letras Português e Matemática).

Nesse contexto, algumas questões surgiram quanto ao territoriolicenciatura ${ }^{4} \mathrm{e}, \mathrm{com}$ essa inquietação, indagamos à pró-reitora de ensino do Ifes, em 2017, quanto a possíveis preferências dos campi do Ifes em ofertar cursos de bacharelado em detrimento das licenciaturas, e assim ela afirmou:

Quando você pergunta se há diferença de aceitação dos campi na oferta dos cursos de licenciatura... Geralmente os campi querem abrir outros cursos mesmo [...]. Para mim, a licenciatura é a profissão que mais deveria ser valorizada [...]. Mas, infelizmente, não é assim que a gente trabalha no Brasil. Sempre a preferência é por abrir outros cursos, bacharelado, principalmente (PRÓ-REITORA DE ENSINO, 2017).

Nesse sentido, problematizamos: o que está anunciado em uma afirmação como essa? Com Deleuze e Guattari (2011) nos sustentamos na perspectiva de que não existe enunciação individual, nem mesmo sujeito de enunciação. A enunciação remete, por si mesma, aos agenciamentos coletivos. É sempre um agenciamento que produz os enunciados. "O enunciado é produzido por um agenciamento, sempre coletivo, que põe em jogo, em nós e fora de nós, populações, multiplicidades, territórios, devires, afetos, acontecimentos" (DELEUZE; PARNET, 1998, p. 65).

\footnotetext{
${ }^{4}$ Conforme Guattari e Rolnik (2011), o território é relativo a um sistema, a uma apropriação, a uma subjetivação que faz o sujeito se sentir "em casa", isto é, um conjunto de projetos e representações com comportamentos e investimentos em tempos e espaços sociais, culturais, estéticos e cognitivos.
} 
Acerca da enunciação, problematizamos ainda: que agenciamentos desejantes privilegiam o bacharelado em detrimento das licenciaturas no Ifes como produção coletiva e desejante no que tange ao territoriolicenciatura? Pensamos, com Deleuze e Parnet (1998), que só se deseja em função de um agenciamento no qual se está incluído e, com Simonini (2010, p. 9), que o desejo é “[...] fábrica, produção; é agenciamento contínuo mesmo quando produção de antiprodução". Desse modo, o desejo que engendra um territoriolicenciatura é produzido na relação com um conjunto de paisagens em que se agenciam políticas, normatizações, lógicas econômicas etc. Assim, a subjetividade que emerge nessas paisagens, em especial no territoriolicenciatura, não é uma idealização ou uma forma, mas produção ativa, composição de forças, nomadismo. A subjetividade não é uma posse, mas uma produção que acontece entre os encontros vividos entre os corpos (GUATTARI; ROLNIK, 2011).

Com esse entendimento, a licenciatura é um território de singularidades, intensidades e movimentos em que se compõem agenciamentos coletivos de enunciação e um emaranhado de linhas desejantes nas quais somos produzidos e produtores, não sendo possível estar "de fora" para tecer quaisquer análises. Envolvidas como pesquisadoras nessa paisagem das licenciaturas - em especial licenciatura em Matemática do Ifes -, procuramos seguir alguns agenciamentos que engendram as formasforças do territoriolicenciatura, cientes de que "[...] todo agenciamento é, em primeiro lugar, territorial [pois o] território cria o agenciamento e o agenciamento ultrapassa o simples “comportamento"' (DELEUZE; GUATTARI, 1997, p. 128). Nesse pensar-problematizar o territoriolicenciatura no Ifes, procuramos acompanhar agenciamentos coletivos enunciadores da produção de sentido e igualmente de vetores de invenção. Com essa perspectiva, em vez de pensarmos em sujeitos que produzem individualmente os discursos/enunciados, enfatizamos os agenciamentos coletivos de enunciação (produção de sentidos não centrados em agentes individuais).

Assim, a pesquisa buscou dar passagem a agenciamentos coletivos a partir da produção das redes de conversações estabelecidas entre as pesquisadoras agentes da Reitoria do Ifes e agentes do campus (professores, coordenadores do curso, pedagogos) no segundo semestre de 2017, especialmente com os dois orientadores de estágio e 20 licenciandos em Matemática participantes dos encontros do Estágio Supervisionado III (ensino médio) experienciados no primeiro semestre de 2018. 
As estratégias escolhidas para a pesquisa realizada no Estágio Supervisionado III foram: utilização de gravador de voz e diário de campo durante os 11 encontros da turma que ocorreram das $18 \mathrm{~h}$ às $22 \mathrm{~h}$; uso de gravador de voz durante as conversas entre pesquisadores e licenciandos antes e após os encontros coletivos do estágio; e análise dos relatórios individuais entregues pelos alunos na conclusão desse período.

\section{Solução de problemas ou invenção de problemas?}

Pensar as licenciaturas é pensar igualmente nas lógicas que orientam o que vem a ser aprendizagem e inteligência. Talvez compreender inteligência como um processo de solucionar problemas com êxito não seja somente uma descrição utilitarista da inteligência, mas também um fenômeno político repleto de sentido social e econômico. Daí a importância de uma análise mais cuidadosa para confrontar a lógica de pensar a cognição como inteligência bem-sucedida e representação. Cabe destacar que as características apontadas como concernentes a uma inteligência bem-sucedida toma como base uma inteligência prêt-à porter (ROLNIK, 1989), que se forma e se desfaz de acordo com os interesses do mercado.

Para os cognitivistas, resolver problemas para obter sucesso retrata a qualidade da inteligência. Desse modo, a finalidade da solução de problemas é criar sujeitoscompetência eficazes para atuar no mercado, o que significa promover a formação de uma elite executiva, ou seja, a adoção de uma lógica meritocrática. Essa lógica focaliza o talento como possibilidade de "boa" performance e transforma o fracasso em moeda de troca. Quando o fracasso surge, é para ser identificado, capitalizado e localizado para não atrapalhar o funcionamento capitalista que baliza o desempenho.

Nesse processo, os excluídos são todos aqueles que não apresentam as características da inteligência bem-sucedida por déficit ou superação das competências e habilidades. Nos processos curriculares e de docência, o insucesso torna-se moeda de troca, justificando o discurso da meritocracia, ou seja, do insucesso como problema individual que cabe a cada um resolver por meio de seu esforço, desconsiderando os contextos políticos, econômicos e sociais. Moeda de troca, no sentido de que o capitalismo necessita do exército de reserva da massa de subempregados e subeducados, de modo a garantir a manutenção da exploração da força de trabalho. 
No caso dos professores e alunos em formação, os resultados são indicadores de seu fracasso. A qualidade e a quantidade da programação e gerenciamento dos passos mentais que mapeiam o ensino, por sua vez, são indicadores dos processos de recognição. Sendo assim, batem de frente com fatos inquestionáveis: a emergência e a diversidade do cotidiano escolar que é frequentemente modificado; a celeridade do avanço dos conhecimentos que se transformam rapidamente na contemporaneidade.

Assim, habilidades e competências impostas pelos modelos de realidade, que são fomentados na produção de subjetividade capitalística voltada para as lógicas do mercado, deixam de fora a cognição encarnada na experiência e na invenção (KASTRUP, 1999). De acordo com Kastrup (1999, 2005, 2008), para inserir a invenção no campo do aprender, o conhecimento "[...] não pode ser colocado em termos de condições invariantes, de limites intransponíveis, posto que universais e necessários" (KASTRUP, 1999, p. 32), mas deve-se considerar seu fluxo temporal e inventivo que, para além da solução de problemas, trabalha com a perspectiva do acontecimento, da problematização.

Para Foucault (2002, p. 242), a "Problematização [...] é o conjunto das práticas discursivas ou não discursivas que faz alguma coisa entrar no jogo do verdadeiro e do falso e o constitui como objeto para o pensamento". Nesse sentido, o poder de apresentar problemas envolve um grau de participação, configurando-se como um poder de politização: “[...] um poder de introduzir novos objetos e novos sujeitos dentro do espaço da política e de torná-los as balizas de uma polêmica e de uma luta" (LAZZARATO, 2014, p 127).

A leitura deleuziana de Foucault (DELEUZE, 2005) diferencia relações de poder de instituições, considerando o poder, sempre, como uma relação entre forças, e as instituições como agentes de integração e/ou de estratificação dessas forças. Integrar, portanto, significa homogeneizar as singularidades, fazê-las convergir em função de um objetivo comum; e a diferenciação possibilita um outro processo imprevisível e não antecipado: o acontecimento.

Porém, o acontecimento fomenta a problematização e, consequentemente, a invenção de novas coordenadas de mundos. Portanto, um acontecimento não é uma solução antecipada de um problema, mas uma abertura de possibilidades. Possibilidades, contudo, muitas vezes negadas pela burocratização da vida, como quando nos deparamos, tanto no campo do currículo escolar, quanto nos espaços de formação docente, com a forte tendência para a padronização das práticas discursivas e não discursivas que, em nome de 
um modelo estabelecido a priori de competências e habilidades requeridas para um modelo de sucesso profissional, exclui os "ninguéns" e implanta o abandono da diferença e da abertura para a multiplicidade.

São, assim, muitas as tentativas de regulação do currículo e da docência, mas há propostas emergentes de escape e, dentre elas, ressaltamos a perspectiva da cognição como invenção, que ultrapassa o conceito de cognição como apolítica e atemporal. Esta abordagem não se restringe à solução de problemas, mas investe na produção de problemas, inserindo o tempo, o coletivo e a invenção de si e do mundo no movimento do pensar, fazendo da atividade cognitiva uma rede, um rizoma, uma potência inventiva (DIAS, 2011).

Entendemos, com Deleuze (1988), que a diferença e a invenção são conceitos imbricados e que essa invenção, segundo Kastrup (2012), não é um processo cognitivo, mas um modo de entender a cognição. Nesse sentido, os encontrosformação não são processos referentes à solução de problemas; são uma experiência de problematização.

Nessa perspectiva, em consonância com Dias, Barros e Rodrigues (2018), a "formação inventiva" busca problematizar práticas e discursos hegemônicos para engendrar uma posição que coloca tal formação como produções de subjetividades. A formação inventiva, conforme esses pesquisadores, escapa dos núcleos centrais de verdade, das localizações daqueles que sabem o que os outros devem fazer e engendra práticas de desaprender aquilo que nos conforma e nos imobiliza para estarmos atentos ao que nos acontece, ao que nos afeta.

Desse modo, compomos com os possíveis dos encontrosformação visando à produção de bons ${ }^{5}$ encontros e processos inventivos alegres com (futuros) professores, entendendo que tal produção não está em nosso controle e nem é decorrente da simples vontade de quaisquer agentes ou resultado de quaisquer efeitos retilíneos ou cíclicos de ação-reação.

Enfim, investimos em uma percepção que busca escapar dos modelos prescritivos e fundamentalistas, experienciando o aprenderensinar pela problematização, pelo acontecimento, pela experimentação e que concebepratica o currículo e a docência não somente voltados para resultados mensuráveis e capitalizáveis. A perspectiva da cognição

\footnotetext{
${ }^{5}$ Bons encontros são estabelecidos entre corpos que entram em relação por serem permeados por afetos alegres (SPINOZA, 2013) que os potencializam e os levam à ação.
} 
inventiva ou cognição encarnada segue o percurso das experiências de aprendizagem que brotam em sua trajetória experiencial, regida por problematizações constantes, experimentais, em fuga das lógicas deterministas presentes em concepções de currículo e docência que almejam uma padronização de práticas e de maneiras de pensar.

Dessa forma, as políticas de cognição inventiva, em abertura constante para os imprevistos que emergem dos múltiplos e diversos contextos curriculares e da docência, fomentam processos de ensinoaprendizagem que se compõem em meio a agenciamentos desejantes, intensificadores de arranjos e maneiras de sentirpensar potencialmente inusitadas.

\section{As avaliações externas como pontuais na lógica neotecnicista e as invenções dos possíveis na produção dos curriculosdiferença}

Acompanhar esses agenciamentos que organizam o territoriolicenciatura no Ifes é compor um mapa de intensidades; uma cartografia dos arranjos que dão consistências possíveis ao territoriolicenciatura naquela instituição. Seguimos, nesse sentido, práticas e discursos que emergiram nas redes de conversações que foram ativadas nos encontros da disciplina "Estágio Supervisionado III", no curso de Licenciatura em Matemática. E, assim, na cartografia experienciada, notamos que as avaliações externas, principalmente o Programa de Avaliação da Educação Básica do Espírito Santo (Paebes) e o Exame Nacional do Ensino Médio (Enem), eram vivenciadas como ações que enrijeciam e reterritorializavam o currículo das escolas de ensino médio no estado do Espírito Santo conforme relatório do licenciando:

Devido à exigência do sistema de educação em avaliar os alunos por meio da prova do Paebes, o [nome do docente regente da escola] mudou a ordem dos conteúdos do ano letivo, se comparado a anos anteriores, na tentativa de melhorar as notas dos alunos no Paebes. Sobre esses conteúdos cobrados nas provas, [nome do professor regente] comentou que essas informações ele mesmo teve que buscar no site, pois não há um diálogo entre organizadores do Paebes e as escolas, e um professor iniciante ficaria perdido na obtenção de informações e seria cobrado dele o desempenho dos alunos [nessa] prova. 
Nesse relato, temos que as forçasformas que atravessaram o processo de avaliação narrado pelo licenciando parecem ter composto nele um afeto triste 6 (SPINOZA, 2013), diante da vivência da pressão sentida, junto a professores do ensino médio, das lógicas que instauram um utilitarismo na educação. Nessas linhas enrijecidas, alguns estudantes foram afetados pela tristeza, por não compactuarem com o império da sujeição das escolas aos rankings, às formações neotecnicistas do currículo. Um desses licenciandos declarou: "Na minha percepção, enquanto professora, senti uma verdadeira angústia de ter que participar de um sistema tão unilateral e desumano como esse e pensei: 'Não é isso que eu quero para minha vida como docente [...]'. É muito desgastante".

Acompanhando esses percursos, encontramos licenciandos que, por vezes, atravessados por esses afetos tristes, anunciavam sua desistência da prática docente pelo receio de não conseguir romper com essas racionalidades e inventar caminhos possíveis nas fissuras dessas linhas enrijecidas: "Sinceramente, desisti daquele emprego para mim [...]. Foi ali que eu decidi. Por isso que é bom estágio: recuperação, recuperação da recuperação e ainda vem o pedagogo querer o plano de aula?!". De acordo com um dos licenciados:

Durante esse período [do estágio da Licenciatura], nas turmas por mim observadas, foi muito claro que a professora se sente prisioneira de um Sistema de Ensino [...]. É o tempo todo o professor preocupado com avaliações, registros, simulados e recuperação [...]. A preocupação com as notas estarem lançadas - de preferência com bons resultados - é bem caracterizada na fala da pedagoga [...]. Os resultados da avaliação diagnóstica, feita no início do ano, são comentados para que os professores façam uma recuperação das notas obtidas.

Nesse cenário, os licenciandos narraram uma condição de professor que se coloca na fronteira entre uma racionalidade, que exige rendimento com foco nas avaliações externas, e os alunos, que são submetidos ao controle docente como modo para manter a atenção aos conteúdos apresentados:

Parece que aprender o que vai cair no Paebes é mais importante do que aprender o que está no currículo (LICENCIANDO 1).

\footnotetext{
${ }^{6}$ Enquanto os afetos alegres nos levam à ação, os afetos tristes são os que nos levam à paralisação.
} 
É! Eu não consigo entender isso. Eu não estou falando que eu estou no fim de carreira, não, mas isso era o que mais me decepcionava no ensino médio: eles vinculam as avaliações oficiais ao currículo da escola e do professor. O professor fica amarrado, ele quer dar aquele salto, mas ele não consegue porque é uma cobrança muito grande em cima do professor com relação a essas notas (LICENCIANDO 2).

É! Eu não sou professor... Se eu já fosse, eu queria ter muita, muita força para conseguir romper com essa prova e falar: 'Dane-se essa prova' (LICENCIANDO 3).

Assim, esses alunos produziram conversações que se deslocam das concepções culpabilizadoras dos docentes das escolas, denunciando os Aparelhos de poder das lógicas capitalísticas que tentam controlar os movimentos curriculares sob a égide das avaliações externas como origem-finalidade que desenha seus contornos curriculares. Essa forçatensão, que atravessou o conversar com e entre, nós, aqueles licenciados e o professor orientador do estágio, dava consistência ao surgimento de pensamentos e ações que se revoltavam contra o já instituído nas práticas docentes que, por exemplo adquiriam materialidade em expressões como "Dane-se a prova!".

Durante a pesquisa, percebemos uma associação dessa racionalidade das avaliações com o padrão "par perguntas-respostas prontas (clichês)" e o ensino tradicional(neo)tecnicista que reterritorializam os currículos a partir da recognição e dos afetos tristes em complexas engrenagens da máquina capitalística sobrecodificante em ações de estancamento dos fluxos de pensamento. Desse modo, um dos licenciandos afirmou: "A rotina das aulas de 50 minutos não permite muito diálogo [...]. A sala é muito cheia e o movimento de entrada e saída dos professores é rápido. Não se perde tempo para comentários".

Nessas acepções, percebemos, a partir das conversações com os licenciandos, que as aulas são formatadas dentro de um enquadramento crónos, ${ }^{7}$ que reforça o enrijecimento desse tecido, aprisionando a vida-alunos e a vida-docência, cujas tentativas de respirar de outros modos são, por vezes, sufocadas. Entretanto, os movimentos que os licenciandos faziam nas escolas e trançavam no estágio eram ziguezagueantes e engendrados a outras linhas que também ensejavam desterritorializações e produziam outras subjetividades no

\footnotetext{
${ }^{7}$ Cronos é o tempo da medida, que fixa as coisas e as pessoas, desenvolve uma forma e determina um sujeito. Cronos é o oposto de Aion, que é o tempo indefinido do acontecimento, a linha flutuante que só conhece velocidades e ao mesmo tempo não para de dividir algo que vai passar e acaba de passar (DELEUZE; GUATTARI, 2012).
} 
que tange aos encontrosformação. Ou seja, as linhas moleculares ${ }^{8}$ e linhas de fuga ${ }^{9}$ também estavam presentes nesses enredamentos, entremeando essas produções de subjetividade nos bonsmausencontros com (futuros) professores.

A imagem do pensamento converge às universalizações. Diversamente, o pensamento inventivo é produzido "[...] sem horizonte, como espaço liso, estepe, deserto ou mar" (DELEUZE; GUATTARI, 2012, p. 52). Nesse sentido, as composições cartográficas com os diversos agentes traçavam engendramentos complexos das linhas desejantes molares $^{10}$, moleculares $e$ de fuga, coexistentes nesses movimentos micromacropolíticos os quais produziam, também, fagulhas de novos possíveis.

\section{Entre forças e form-ação docentes: compondo encontrosformação com (futuros) professores e invenções de outras viagens}

Entre as experiências que compartilhamos, quando nos propusemos acompanhar os encontrosformação do Estágio Supervisionado do curso de licenciatura em Matemática do Ifes, percebemos pistas que indicavam que há várias questões coengendradas nessa paisagem movente que desenha o territoriolicenciatura: os enconstrosformação experienciados pelos professores do Ifes, pelos licenciandos, pelos professores das escolas em que os estágios eram praticadospensados e pelos alunos que integram essas escolas e também tecem encontrosformação de aprendizagemensino.

Entre formasforças, buscamos produzir invenções de outras viagens, problematizando a repetição da viagem-modelo imóvel de uma docência-rosto, a ilusão dos passageiros homogêneos e dos destinos únicos e iguais que enrijecem esses processos de encontrosformação. Nesse sentido, ressoamos as aulas como encontros. Conforme Deleuze (1996), as aulas são muito mais do que objetivos, seleção de conteúdos e avaliações. Muitas coisas acontecem em uma aulaencontro. Uma aula não é apenas inteligência. É emoção também. As aulas são encontros, são matérias em movimento, são musicais, são relações.

\footnotetext{
8 Linhas moleculares são as que causam desvios e cortam o plano macropolítico, evidenciando experienciações inusitadas (DELEUZE; PARNET, 1998).

${ }^{9}$ As linhas de fuga são as de tipo desconhecido que nos levam a imprevisibilidades para o que não foi determinado, nem previsto (DELEUZE; PARNET, 1998).

${ }^{10}$ As linhas molares são as que compõem o plano de organização e nos recortam em todos os sentidos (DELEUZE; PARNET, 1998).
} 
Nesse sentido, as falas dos licenciandos a seguir exemplificam que esse espaço é de relação, conexão, agenciamento, mistura de afetos, de encontros, de redes de conversações, de sentidos múltiplos e singulares: "A [nome da professora em questão] tem essa facilidade de se relacionar com os alunos [...]. Ela está sempre atualizada com as problemáticas que acontecem dentro da sala de aula [...] ela tem essa sensibilidade". "O estágio ajuda a gente na forma como a gente está lidando com as pessoas, a interação mesmo: aluno-aluno, professor-professor, professor-aluno, coordenador, diretor, pedagogo".

Assim, acompanhamos o que pode o Estágio Supervisionado, o que pode um corpo para fazer vibrar bons encontros com os licenciandos nas composições complexas trançadas com e entre eles no estágio (no Ifes e nas escolas de ensino médio). Alguns desses fragmentos foram expostos nos escritos desses estagiários: "O estágio propicia uma profunda reflexão [...]. Isso é analisado a partir da vivência que temos dentro da escola que nos acolheu para o estágio".

Entendo que cada escola é um microcosmo em si [...]. Entender as particularidades de cada aluno, perceber nuances sutis e quase imperceptíveis a estranhos - e até a si mesmo - quando se muda de humor ou se compreende algo, sentir-se parte da vida dos estudantes, e mesmo as frustrações de não conseguir atingir determinada meta ou ambição são sensações únicas que jamais experimentaria unicamente sentada nos bancos da universidade. Sendo honesta, não as vivenciaria em nenhum outro lugar ou tempo. A escola é, sim, um lugar único. É somente nela e com a permissão do estágio que compreendi a intensa necessidade da socialização dos alunos e a importância da multiplicidade de pensamentos, culturas e personalidades em uma sala (LICENCIANDO).

Conforme expressaram os agentes alunos, o Estágio Supervisionado é um espaço para conhecer as singularidades das escolas e experienciar esses cotidianos em um contato vivo e único que não pode ser previsto nos momentos em que se estudam as diferentes disciplinas que integram o curso de graduação. Os licenciandos demonstraram, ainda, que há possibilidades de experienciar criações coletivas a partir dos receios e outros afetos produzidos nas escolas - que são explicitados no grupo pesquisado e pensados entre produções múltiplas. 
Algumas das aulas ministradas pelos licenciandos no estágio também desenharam alternativas que escapavam ao padrão e inventavam outros caminhos curriculares nos encontrosformação com licenciandos e professores. A primeira aula ministrada por uma das alunas, por exemplo, consistiu em deslocar a Matemática de alguns dos rótulos que por vezes produzimos acerca desse saber, a partir da relação estabelecida entre o conceito de "Tecelagem", de cultura e datas comemorativas, como o "Dia da consciência negra", com a Matemática. Essa aula se iniciou assim: "Tecelagem é a arte de produzir tecidos. Tecer é entrelaçar. Então, nós vamos discutir a origem da Tecelagem Africana e a importância da tecelagem na cultura africana e seu simbolismo".

Inicialmente, isso estilhaçava o clichê, o que era esperado nas enunciações produzidas acerca do modelo-Matemática. A aula foi composta de encontros com Arte, Língua Portuguesa, enunciados sobre "tecer, entrelaçar", História da Matemática, questões étnico-raciais. Desse modo, percebemos o que pode o Estágio Supervisionado nas licenciaturas fazer ressoar para pensarpraticar as produções de conhecimento, os encontros com a Matemática de múltiplas maneiras que escapam ao clichê.

No estágio também há possibilidades de experienciar criações coletivas, a partir dos receios e outros afetos produzidos nas escolas - que são explicitados no grupo e pensados entre produções múltiplas. É nesse sentido que evidenciamos o fragmento da conversação abaixo, na ocasião em que uma agente estudante expressou uma dificuldade durante a sua regência e a colega licencianda interveio.

Um desafio para mim: eu sou tímida. Eu não consigo me relacionar tanto com os alunos.

$[\ldots]$

Vou te dar uma dica: é só você dar abertura para eles [estudantes do ensino médio]. Quando você dá abertura para eles, vão vir e vão começar a falar.

Além dessas relações de aprendizagemensino, produzidas com os próprios colegas licenciandos, no espaço do estágio também ocorreram intervenções que fizeram reverberar a importância desses encontros, para questionar praticaspensamentos que são constantemente reproduzidos a partir da fala de um dos professores orientadores:

$\mathrm{Na}$ sala de aula, nós temos que desmitificar isso: 'O aluno foi mal!' Gente, vamos eliminar do nosso vocabulário essa palavra 'dificuldade'. Nosso papel é levá-lo à frente, levá-lo adiante na aprendizagem. Se 
sempre ficar pontuando 'O aluno foi mal', 'Ele tem dificuldade', o aluno vai assimilar esse discurso de que ele foi mal, de que ele não sabe. Não existe problema de aprendizagem [...]. Enfim, pensem nisso! Porque isso é uma coisa muito séria. A gente pega TCC [Trabalho de Conclusão de Curso] de alunos para ler, e a primeira coisa que colocam é que 'o aluno tem dificuldade de aprender Matemática'. Todo mundo escreve isso! Como mudar isso? Esses dias, uma editora me mandou a cópia de um rascunho de um livro que iria ser publicado. Na introdução do livro - é para alunos de licenciatura em Matemática - estava lá que 'Os alunos chegam ao curso de Matemática sem saber Matemática' e que 'Os alunos têm dificuldade' e vai falando isso o tempo todo... Isso é sério!

Nos trechos acima, pudemos perceber ressonâncias do que pode o estágio nos movimentos de pensamento dos encontrosformação nos cursos de licenciatura em Matemática. Alguns desses movimentos produzidos na regência dos estudantes também foram salientados na fala de um dos orientadores que afirmou que o processo ensinoaprendizagem não é uma sequência de perguntas-respostas e que é importante "[...] não partir de algo esquematizado". Ou seja, não iniciar com respostas e nem apenas com perguntas para as quais as respostas esperadas já estão previamente colocadas.

Nessas aulasencontros com licenciandos, produzimos experimentações que deram passagem a pequenos acontecimentos que estilhaçavam clichês por movimentarem o pensamento para outros modos de praticarpensar a Matemática, a aprendizagemensino, a arte de fazerpensar a docência a partir dessas conversas e se fazer docente no corpo coletivo enredado entre escolas de ensino médio e seus agentes e Ifes e seus agentes.

Compomos com o entendimento de que os encontrosformação são produzidos entre relações micromacropolíticas (DELEUZE; GUATTARI, 2012) e em inúmeros espaçostempos formativos nos quais os licenciandos transitam e os (des)formam. A política é um ethos, um modo de existência. Com Nilda Alves (2010), entendemos que políticas são práticas, sempre coletivas, e há uma variedade de contextos em que essas praticaspoliticasformação acontecem e esses espaços são agenciados de modo que não podemos controlá-los e eles se influenciam. Com Deleuze (1992, p. 214), afirmamos que o político é possibilidade, acontecimento, singularidade e que "[...] há curto-circuitos que abrem o presente para o futuro. E que modificam, portanto, as próprias instituições."

Assim os encontrosformação ocorrem em múltiplos espaçostempos: no encontro com as práticas da formação acadêmica; o das práticas pedagógicas cotidianas nas escolas em que estagiaram; o das práticas políticas de governo; com as práticas políticas coletivas dos movimentos sociais; e o das práticas das pesquisas em educação. Nesse sentido, 
lembramos de um dos fragmentos das redes de conversações que estabelecemos com os licenciandos e o professor orientador do Estágio Supervisionado em Matemática:

O governo [do Espírito Santo] anterior tinha o 'Multicurso de Matemática'. Os professores eram pagos. Depois, o mesmo governador, e mesmo secretário [de Educação do Espírito Santo] tiraram esse projeto e preferiram investir em Olimpíadas [de Matemática] [...]. Não tem formação continuada (PROFESSOR).

Formação de professores não dá Ibope. Não aparece na Gazeta [nome de um jornal situado no Estado do Espírito Santo], mas Olimpíadas, sim (LICENCIANDO).

Desse modo, evidenciamos que entre esses aspectos se compõem diversas paisagens micromacropolíticas nacionais, estaduais, municipais, atinentes aos contextos das escolas, das universidades, dos institutos federais, produzidas antes e após a conclusão do curso de graduação, tecendo, assim, complexos agenciamentos nesses espaçostempos em que se entrecruzam professores, alunos, futuros professores e outras pessoas.

No que concerne a essas composições micromacropolíticas, ainda que não tenha sido nosso objetivo neste trabalho discutir programas de governo para a Educação, o Programa Institucional de Bolsas de Iniciação à Docência (Pibid) - no formato em que foi ofertado nacionalmente até 2017 - apareceu com muita força nas conversas que trançamos com coordenadores de curso, professores e licenciandos como potência nas relações tecidas entre o curso de licenciatura do Ifes e as escolas: "Eu tive uma participação bem ativa no planejamento nas atividades, mais uma relação de colegas de trabalho, de parceria porque participei do Pibid na escola".

Coincidiu de 2010 a gente começar a implementar aqui o Programa do Governo Federal, o Pibid [...]. O Pibid foi uma oxigenação no curso que você nem imagina. Tanto para os alunos, quanto para nós, professores, porque a gente sempre defendeu aquela ideia desde o início: a gente precisa ter um vínculo muito estreito com a educação básica, com as escolas [...]. No estágio, a gente consegue, a duras penas, entrar nas escolas parceiras, mas não é fácil. Então, o Pibid traz essa articulação muito fácil: do espaço da formação da licenciatura com a escola básica [...]. A partir de 2011, as escolas perguntavam: 'Não vai trazer mais aluno para cá?'. A escola que sabia que tinha Pibid em outra escola dizia: 'A minha escola também quer. A gente está precisando'. Então, foi um projeto que, para formação, foi muito bom, porque atendeu aos alunos até em questões socioeconômicas (COORDENADOR DE CURSO DE LICENCIATURA EM MATEMÁTICA). 
Fazer parte do Pibid foi um ponto importante para dar continuidade na faculdade e na carreira, pois, a cada momento com aqueles alunos, me fizeram pensar na realidade do que é ser professora e nas dificuldades encontradas dentro de uma sala de aula. No decorrer de minha permanência no programa, acompanhei por mais de dois anos a realidade daqueles alunos e professores no ambiente escolar, confirmando o meu desejo em manter firme em minha jornada (LICENCIANDO).

Nos relatos escritos dos licenciandos essas pistas também foram delineadas: "O curso de licenciatura em Matemática me ajuda a ampliar minha visão sobre a prática docente mediante a articulação dos conceitos pedagógicos com as experiências que obtenho por meio do Pibid e do Estágio Supervisionado". Conforme expresso no relatório de outros estudantes, o Pibid não contribuiu apenas para o processo de aprendizagem deles, mas, inclusive, na produção de conhecimentos dos alunos do ensino médio, como exemplifica a escrita, a seguir:

Neste tópico, percebo uma clara diferença entre a atuação dos alunos que vivenciaram o contato com bolsistas do Pibid e aqueles que não tiveram. Isso se torna claro, pois, nas turmas de terceira série [na qual os estudantes já tinham recebido alunos do Pibid], os alunos questionam a professora, participam ativamente das atividades, perguntam aos estagiários [...], entre outras coisas.

Os licenciandos enfatizaram a importância do Pibid para pensar com as escolas, para conhecer o próprio curso, para pensar sobre a docência, para diminuir a evasão entre outras justificativas: "A pouca experiência que adquiri em sala de aula foi por meio do Pibid".

A partir do $2^{\circ}$ período, iniciei no Pibid, onde comecei a interagir um pouco mais com colegas e professores. Mesmo com certa dificuldade, prossegui com o meu propósito em ser professora, e foi neste programa que tive o primeiro contato com a sala de aula [...]. Fazer parte do Pibid foi um ponto importante para dar continuidade na faculdade e na carreira, pois, a cada momento com aqueles alunos, eles me fizeram pensar na realidade do que é ser professora e nas dificuldades encontradas dentro de uma sala de aula. No decorrer de minha permanência no programa, acompanhei por mais de dois anos a realidade daquelas crianças e professores no ambiente escolar, confirmando o meu desejo em manter firme em minha jornada. 
Serei honesta ao admitir que iniciei o curso sem qualquer expectativa. Absolutamente nenhuma [...]. E, admito, cultivei este pensamento até iniciar no Programa Institucional de Bolsa de Iniciação à Docência, o Pibid, e sentir o acolhimento do aluno, seu carinho e esperança. Algo que, francamente, nunca senti igual em nenhuma ocupação que possuí.

Entretanto, o Pibid - veementemente ressaltado nas falas e escritos dos alunos de licenciatura, dos professores do estágio e coordenadores do curso de licenciatura em Matemática -, criado em 2007, no governo Lula, pelo Ministério da Educação, com o objetivo de contribuir na formação de estudantes de licenciatura plena das Instituições Federais e Estaduais de Educação Superior, inserindo-os no contexto de iniciação à docência no ambiente escolar, foi redesenhado.

Em 2018, as bolsas passaram a ser destinadas às instituições de ensino superior privadas também, e o investimento, além de reduzido, foi dividido entre um Pibid reformulado e o Programa de Residência Pedagógica, no qual - diversamente do Pibid - os estudantes passaram não apenas a acompanhar as regências, mas também a exercer um trabalho professoral, ainda "mais barato" do que já o era (ao ser realizado pelos professores - profissionais graduados) antes dessa nova lógica do programa que enfraquece os movimentos de valorização docente (BRASIL, 2018). Assim, novamente pensamos nos engendramentos das danças micromacropolíticas no campo dos encontrosformação com (futuros) professores entre os múltiplos espaços em que transitamos.

A partir dos dados produzidos, compartilhamos uma proposta que visa a fraturar o entendimento de política associada ao acento no "é" (representação, identidade, rosto, respostas imutáveis, solução do par "perguntas-respostas verdadeiras") para compor com o "e" entre esses inúmeros encontrosformação e, principalmente, no que se refere à especificidade desta pesquisa: as conexões nos "estágios supervisionados-licenciaturas $e$ escolas".

Em consonância com Garcia e Sussekind (2011), os licenciandos, por meio dos relatórios individuais, ratificaram que o ensinoaprendizagemformação não é reduzido a momentos lineares, estanques, com certificações; é um processo político permanente que acontece ao longo da vida e que envolve múltiplos espaços. "Percebo que meus saberes de hoje não serão os mesmos de amanhã e que a cada ambiente estou me refazendo [...]. E pensando assim, estou mais aberta a mudanças, com menos pensamentos fechados. A experiência em sala de aula traz, sobretudo, uma reaprendizagem”. 
Nesse caminhar, compartilhamos a noção de formação com licenciandos como abertura aos encontros e às experimentações, baseadas no entendimento de que o Estágio Supervisionado é um espaço profícuo a essas composições devido às relações tecidas com as escolas e com as problematizações que poderiam acontecer/acontecem entre as redes de conversações complexas coletivas. Essas aberturas, sobre as quais conversamos, não significam vazios ou falta de bases epistemológicas acerca da docência ou de quaisquer espontaneísmos, entretanto são teoriaspráticas que, agenciadas no afetar dos corpos, transitam nessas conversas nos encontrosformação a partir das vivências escolares e podem desterritorializar modelos e fazer lampejar novos possíveis nos processos de aprendizagemensino nômades (DELEUZE, 1992) nos movimentos de pensamento estudantis expressos, também, nos escritos individuais:

\begin{abstract}
Agente estudante: Começo me reportando novamente a Esteban: 'Entrando na sala de aula, em qualquer uma das imagens de que dispomos, encontramos a compreensão, por parte dos docentes, de que seus alunos e alunas são diferentes, possuem ritmos diferentes de aprendizagem, trazem para a escola saberes diferentes, vivem em contextos diferentes, como participantes de arranjos familiares também diferentes. Diferente torna-se uma palavra naturalizada na sala de aula, como se portadora de um único sentido; como se destituída do conteúdo ambíguo e conflituoso que carrega. A diferença parece compor o ambiente da sala de aula, em harmonia com seu mobiliário, em consonância com as práticas ali realizadas, sendo levada e trazida a cada dia nas mochilas de cada um' (ESTEBAN, 2006, p. 9). Digo isso pelo fato de ver novamente, como estagiária, agora no Ensino Médio da Rede Estadual de Educação, que, dentro daquelas mochilas que os jovens e adolescentes carregam, cada um com suas histórias, suas angústias e seus desejos e sonhos - que são tão diferentes - são igualados e enclausurados.
\end{abstract}

Não há receitas que possam fazer a licenciatura “funcionar" em um pensamentodiferença. Ainda assim, apesar de não propormos um modelo de formação para os professores no Brasil, e/ou para os cursos de licenciatura nos institutos federais, e/ou para os estágios supervisionados, entendemos que os espaçostempos de encontrosformação dos licenciandos nos Estágios Supervisionados poderiam ser mais potentes, se tivéssemos mais tempo dedicado às conversações, análises e produções de pensamento dos estudantes, porque, coletivamente, poderíamos produzir mais problematizações e compor com e entre essas danças de pensamento, experiências, invenções, experimentações, curriculosdiferença. 


\section{Em encontros sem fim...}

Esta pesquisa não buscou problematizar "modelos de formação de professores" no contexto das licenciaturas em Matemática do Ifes, entretanto compor com o pensamentodiferença e a potência das redes de conversações nos Estágios Supervisionados dos cursos de licenciatura, a fim de fazer ressoar o que pode um corpo em encontrosformação com (futuros) professores.

Assim, a experiência singular vivida no campus/curso escolhido não deve ser generalizada e transporta como decalque e colagem para outras paisagens (seja em institutos, seja em universidades). O que desejamos propagar - a partir da pesquisa local é que, em qualquer lugar em que se intente praticarpensar encontrosformação com professores e licenciandos, haja espaçostempos para conversar e conversar, problematizar, desterritorializar e compor com o outro (professores das escolas, colegas licenciandos, professores dos estágios, pesquisadores e...) com vistas ao pensamentodiferença produzido no coletivo que pode, como corpo, quebrar solos petrificados e lógicas neotecnicistas que estão sob a nova roupagem das habilidades e competências.

A partir dos fios que escaparam, tentamos compor dissonâncias e movimentos não repetitivos. Assim, experimentamos melodias que, no gritar "Dane-se a prova!", insistiam em fugir dos enquadramentos dos planos de organização. Ainda que os ensaios expressivos, que ganharam corporeidade nas conversações engendradas, apareçam como pequenos fragmentos de interrupção, de irrupção -, essas linhas moleculares e de fuga podem, na força do coletivo, produzir um acontecimento.

Nesse sentido, buscamos, no coletivo, fazer ressoar: o pensamentodiferença, a experimentação coletiva, as singularidades, as multiplicidades, as redes de conversações e o pensamento como potências para a constituição dos Estágios Supervisionados, com vistas a ampliar os processos inventivos na relação emaranhada entre institutos federais, escolas de educação básica e tantos outros espaços complexos de aprendizagemensino e de encontrosformação.

\section{REFERÊNCIAS}


ALVES, N. A compreensão de políticas nas pesquisas com os cotidianos: para além dos processos de regulação. Revista Educação e Sociedade, Campinas, v. 31, n. 113, p. 11951212, out./dez. 2010.

BRASIL; Capes. Pibid e Residência Pedagógica incluem instituições privadas com fins lucrativos. Disponível em: <http://www.capes.gov.br/sala-de-imprensa/noticias/8793pibid-e-residencia-pedagogica-incluem-instituicoes-privadas-com-fins-lucrativos $>$. Acesso em: 15 maio 2018.

DELEUZE. G. Conversações. Tradução de Peter Pál Pelbart. São Paulo: Ed. 34, 1992.

Diferença e repetição. Tradução de Luiz Orlandi e Roberto Machado. Rio de Janeiro: Graal, 1988.

Foucault. São Paulo: Brasiliense, 2005.

DELEUZE, G.; PARNET, C. Diálogos. Tradução de Eloísa Ribeiro. São Paulo: Escuta, 1998.

DELEUZE, G; GUATTARI, F. Mil platôs: capitalismo e esquizofrenia. São Paulo: Editora 34, 1997. v. 1.

Mil platôs: capitalismo e esquizofrenia 2. Tradução de Ana Lúcia de Oliveira e Lúcia Cláudia Leão. São Paulo: Editora 34, 2011. v. 2.

Mil platôs: capitalismo e esquizofrenia 2. Tradução de Aurélio Guerra Neto, Ana Lúcia de Oliveira, Lúcia Cláudia Leão e Suely Rolnik. São Paulo: Editora 34, 2012, v. 3.

DIAS, R. O. Deslocamentos na formação de professores: aprendizagem de adultos: experiência e políticas cognitivas. Rio de Janeiro: Lamparina, 2011.

DIAS, R. O.; BARROS, M. E. B.; RODRIGUES, H. C. B. A questão da formação a partir de 'Proust e os signos' - o acaso do encontro e a necessidade do pensamento. Educação Temática Digital, Campinas, SP, v. 20, n. 4, 2018, p. 947-962.

FOUCAULT, M. A arqueologia do saber. Rio de Janeiro: Forense Universitária, 2002.

GARCIA, A.; SUSSEKIND, M. L. (Org.). Universidade-escola: diálogo e formação de professores. Petrópolis, RJ: De Petrus et Alii; Rio de Janeiro: Faperj, 2011.

GUATTARI, F.; ROLNIK, S. Micropolítica: cartografias do desejo. Petrópolis: Vozes, 2011.

KASTRUP, V. A invenção de si e do mundo: uma introdução do tempo e do coletivo o estudo da cognição. Campinas: Papirus, 1999.

Políticas cognitivas na formação do professor e o problema do devir-mestre. Educação e Sociedade, Campinas, v. 26, n. 93, p. 1273-1288, set./dez. 2005.

KASTRUP, V.; TEDESCO, S.; PASSOS, E. Políticas de cognição. Porto Alegre: Sulina, 2008 . 
LAZZARATO, M. Signos, máquinas, subjetividades. São Paulo: Edições Sesc: n.1, 2014.

ROLNIK, S. Cartografia sentimental: transformações contemporâneas do desejo. São Paulo: Estação Liberdade, 1989.

SIMONINI, E. Variações sobre o “eu”. Teias, Rio de Janeiro, ano 11, n. 21, jan./abr. 2010.

SPINOZA, B. Ética. Tradução de Tomaz Tadeu da Silva. 3. ed. Belo Horizonte: Autêntica Editora, 2013. Edição bilíngue: latim/português.

Recebido: 05/03/2019

Aceito: 30/03/2019 